\title{
Formation and properties of reaction layers of cobaltite electrodes on bismuth oxide electrolytes
}

\author{
V.V. Kharton*, E.N. Naumovich, V.V. Samokhval \\ Institute of Physico-Chemical Problems, Belarus State University, 14 Leningradskaya Str., 220080 Minsk, Belarus
}

Received 18 June 1996; accepted 10 March 1997

\begin{abstract}
Interaction of electrodes consisting of perovskite-like rare earth elements (REE) and strontium cobaltites with $\mathrm{Bi}_{0.75} \mathrm{Y}_{0.25} \mathrm{O}_{1.5}$ solid electrolyte has been studied. Formation of solid solutions $\mathrm{La}_{1-x-x} \mathrm{Sr}_{x} \mathrm{Bi}_{y} \mathrm{CoO}_{3-\delta}(x=0-0.5 ; y=0-0.1)$ as well as $\left(\mathrm{Bi}_{1-x} \mathrm{Co}_{x}\right)_{1-y} \mathrm{Y}_{y} \mathrm{O}_{1,5}(x=0-0.4 ; y=0-0.25)$ can occur in the diffusion layer between cobaltite electrodes and $\mathrm{Bi}_{2} \mathrm{O}_{3}$-based solid electrolytes. The crystal structure, electrical conductivity and oxygen permeability of these solid solutions have been investigated. It has been found that the values of the conductivity and oxygen permeability of $\mathrm{La}(\mathrm{Sr}, \mathrm{Bi}) \mathrm{CoO}_{3-\delta}$ solid solutions decrease with increasing bismuth content. The results of the investigation of polarization resistance of oxide electrodes in contact with $\mathrm{Bi}_{0.75} \mathrm{Y}_{0.25} \mathrm{O}_{1.5}$ solid electrolyte are presented.
\end{abstract}

Keywords: Bismuth oxide; Electrode; Cobaltite; Perovskite; Diffusion

\section{Introduction}

Rare earth element (REE) and strontium cobaltites with perovskite-like structures are promising materials for solid oxide fuel cells [1-3] and oxygen membranes $[4,5]$ owing to their high electronic and oxygen ionic conductivity and high electrochemical activity. Harnessing of cobaltites in electrochemical cells with solid electrolytes based on bismuth oxide seems to hold great promise since the thermal expansion coefficients of the given materials are sufficiently close [6-8]. It has been found in [6] that spray-coating of cobaltite electrodes from a solution of nitrates provides electrode layers with better properties as compared with painting. Impedance

\footnotetext{
${ }^{*}$ Corresponding author. Fax: + 375172 265567; e-mail: kharton@phchinst.belpak.minsk.by
}

spectroscopy demonstrated that interaction between ionized oxygen atoms chemisorbed on the electrode surface and oxygen vacancies is the rate limiting step of cathodic process in cells with $\mathrm{Bi}_{0.77} \mathrm{Y}_{0.23} \mathrm{O}_{1.5}$ solid electrolyte and $\mathrm{La}_{0.5} \mathrm{Sr}_{0.5} \mathrm{CoO}_{3-\delta}$ electrodes [6]. For $\mathrm{La}(\mathrm{Sr}) \mathrm{CoO}_{3-\delta}$ electrodes on $\mathrm{Bi}(\mathrm{Er}) \mathrm{O}_{1.5}$ solid electrolytes, diffusion of atomic oxygen was found to be the limiting stage at high temperatures and charge transfer at low temperatures [7].

The objective of the present work was further investigation of the properties of electrode layers composed of cobaltites of rare earth elements (REE) and strontium $\mathrm{Ln}(\mathrm{Sr}) \mathrm{CoO}_{3-\delta}(\mathrm{Ln}=\mathrm{La}, \mathrm{Pr}, \mathrm{Nd})$ and $\mathrm{SrCo}(\mathrm{Fe}, \mathrm{Cu}) \mathrm{O}_{3-\delta}$, where $\delta$ is oxygen nonstoichiometry. The results of the investigations of structure, oxygen non-stoichiometry, electrical conductivity, thermal expansion and oxygen permeability of ceramics composed of these 
solid solutions were published previously [8-10]. Cobaltites $\quad \mathrm{La}_{0.7} \mathrm{Sr}_{0.3} \mathrm{CoO}_{3-\delta}, \quad \mathrm{Pr}_{0.5} \mathrm{Sr}_{0.5} \mathrm{CoO}_{3-\delta}$, $\mathrm{Nd}_{0.5} \mathrm{Sr}_{0.5} \mathrm{CoO}_{3-\delta}, \quad \mathrm{SrCo}_{0.5} \mathrm{Fe}_{0.5} \mathrm{O}_{3-\delta} \quad$ and $\mathrm{SrCo}_{0.6} \mathrm{Fe}_{0.2} \mathrm{Cu}_{0.2} \mathrm{O}_{3-\delta}$ which offer maximum electrical conductivity in the corresponding systems [810] were chosen for the investigation of electrode properties. The results of the studies of electrode polarization resistance in contact with $\mathrm{Bi}_{0.75} \mathrm{Y}_{0.25} \mathrm{O}_{1.5}$ solid electrolyte have been published in our previous papers $[8,10]$. The present paper is concerned with further investigation of the properties of both cobaltite electrodes and the intermediate phases formed between the electrode and the $\mathrm{Bi}_{2} \mathrm{O}_{3}$-based electrolyte.

\section{Experimental}

\subsection{Investigation of the ceramic samples}

The procedures of synthesis, investigation of crystal structure and composition of sintered powders, methods of making ceramics from the electrode materials and gas-tightness control, procedures for the investigation of electrical conductivity and thermal expansion of ceramic specimens are described in detail in our earlier works [8-11]. In the present work, data on X-ray diffraction (XRD) studies are reported only for specimens calcined in air at $1073 \pm 10 \mathrm{~K}$ for $4 \mathrm{~h}$ and cooled slowly (cooling rate below $80 \mathrm{~K} \mathrm{~h}^{-1}$ ) prior to the investigations. Such a preparation of samples was done to avoid the quenching of phase composition and to obtain materials for which the oxygen sublattice is in equilibrium with oxygen in the gas phase at low tempera- tures. The procedure for oxygen permeability measurements is described in detail in [9]. The methods used for investigation of electrical conductivity and ion transference numbers of solid electrolytes and mixed conductors are covered adequately in [11].

\subsection{Preparation and investigation of the electrode layers}

Two methods were used for the preparation of electrode layers on solid electrolyte substrates having compositions $\mathrm{Bi}_{0.75} \mathrm{Y}_{0.25} \mathrm{O}_{1.5}$ and $\mathrm{Zr}_{0.90} \mathrm{Y}_{0.10} \mathrm{O}_{1.5}$ : coating of the sample by a paste composed of electrode material and organic binding agent with subsequent calcining (method 1) and dispersion of the solution of nitrates over heated solid electrolyte substrate (method 2).

Carefully ground powders of the synthesized complex oxides (particles size no more than $15 \mu \mathrm{m}$ ) with addition of 5 weight $\%$ of organic binder were utilized for preparation of electrodes by method 1 . Acetone or ethanol was used as a solvent. Only single-phase materials whose structure had been verified by the $\mathrm{X}$-ray diffraction method were used for electrode preparation. The peculiarities of the crystal structure of the perovskite-like oxides used in the present work are described elsewhere $[8,9]$. The conditions of thermal processing of electrode layers and corresponding surface densities are listed in Table 1. Temperature, sintering duration and heating rate were chosen in the course of experiments with the objective of providing the necessary extent of attachment and mechanical strength of electrode layers and to minimize interaction of electrode materials with the solid electrolyte substrate.

Table 1

Conditions for the applcation of electrode layers by the method of paste sintering (method 1)

\begin{tabular}{|c|c|c|c|c|c|}
\hline \multirow[t]{2}{*}{ Electrode } & \multirow[t]{2}{*}{ Electrolyte } & \multicolumn{3}{|c|}{ Conditions } & \multirow{2}{*}{$\begin{array}{l}\text { Surface density } d_{\mathrm{s}} \\
\left(\mathrm{mg} \mathrm{cm}^{-2}\right)\end{array}$} \\
\hline & & $T(\mathrm{~K})$ & Time $(\mathrm{h})$ & Heating rate $(\mathrm{K} / \mathrm{min})$ & \\
\hline \multirow[t]{2}{*}{$\mathrm{Ln}(\mathrm{Sr}) \mathrm{CoO}_{3-\delta}$} & BiYo " & 1190 & 0.2 & $60-70$ & $10-80$ \\
\hline & $\mathrm{ZrYO}^{b}$ & 1520 & $2-3$ & $3-5$ & $10-80$ \\
\hline $\mathrm{SrCo}(\mathrm{Fe}, \mathrm{Cu}) \mathrm{O}_{3-\delta}$ & $\mathrm{BiYO}$ & 1060 & $0.5-2$ & $5-7$ & $10-50$ \\
\hline $\mathrm{BiCYO}$ & $\mathrm{BiYO}$ & 1150 & $1-2$ & $5-7$ & $10-40$ \\
\hline $\mathrm{Ag}$ & BiYO & 930 & 0.5 & $3-6$ & $8-15$ \\
\hline
\end{tabular}

${ }^{a} \mathrm{BiYO}-\mathrm{Bi}_{075} \mathrm{Y}_{0.25} \mathrm{O}_{15}$.

" $\mathrm{ZrYO}-\mathrm{Zr}_{0.90}, \mathbf{Y}_{0.10} \mathrm{O}_{1.5}$.

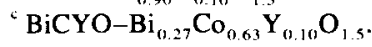


Crystal structure and composition of the electrode layers were determined by $\mathrm{X}$-ray diffraction studies and X-ray fluorescence analysis (XFA). X-ray diffraction studies (XRD) were carried out using a

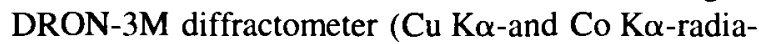
tions, Ni- and Fe-filters respectively). XFA was conducted with the use of a 'Nanolab-7' scanning electron microscope with a SR-860-2 micro-XFA analyzer. Surface and cross-section of electrodes were investigated using electron microscope Nanolab-7 and metallographic microscope MIM-8. Studies of composition and crystal structure of intermediate diffusion layers formed on sintering of $\mathrm{Ln}(\mathrm{Sr}) \mathrm{CoO}_{3-\delta}$ electrodes on $\mathrm{Bi}_{0.75} \mathrm{Y}_{0.25} \mathrm{O}_{1.5}$ solid electrolyte substrates were conducted also using powders scraped from electrode surfaces and using the specially prepared specimens of solid electrolytes with attached electrodes by the method of successive grinding of the ceramic surface to depths of $30-100$ $\mu \mathrm{m}$. For this purpose, cylindrical samples of solid electrolyte $(12 \mathrm{~mm}$ in diameter, $10 \mathrm{~mm}$ in height) were prepared with the electrode layer applied at one of the bases. These specimens were subjected to a more extended sintering than that indicated in Table 1 ( 3 to $8 \mathrm{~h}$ ). This was done to achieve a deeper interdiffusion of the materials. The thickness of the diffusion layer between electrode and electrolyte was 5 to $7 \mathrm{~mm}$ for specimens prepared by this procedure. Other preparation conditions for these specimens did not differ from those indicated in Table 1. Thereafter, layers 30 to $100 \mu \mathrm{m}$ in thickness were ground off sequentially from the surface of specimens thus prepared. The powders obtained by grinding were subject to XFA and XRD studies.

For example, the results of investigations of phase and chemical composition of diffusion layers formed as a result of interaction of $\mathrm{La}_{0.7} \mathrm{Sr}_{0.3} \mathrm{CoO}_{3-\delta}$ electrode and $\mathrm{Bi}_{0.75} \mathrm{Y}_{0.25} \mathrm{O}_{1.5}$ electrolyte at various distances from the electrode surface are shown in Table 2. The distance from the center of the polished-out part of the diffusion layer to the electrode surface $(L)$ is divided by the total thickness of the diffusion layer $\left(L_{0}\right)$ the latter being determined at various crosssections using the metallographic microscope. The relative quantities of different phases forming the diffusion layer was estimated qualitatively from the ratio of $100 \%$ reflections of phases in X-ray diffraction spectra.

Preparation of electrode layers by method 2 consists in the dispersion of a concentrated solution of nitrates, prepared by dissolution of the synthesized cobaltites in nitric acid with addition of $10-15$ vol. \%

Table 2

Phase and cationic composition of the diffusion layer between the electrode $\mathrm{La}_{0.7} \mathrm{Sr}_{0.3 .} \mathrm{CoO}_{3-\delta}$ and the electrolyte $\mathrm{Bi}_{4, .55} \mathrm{Y}_{0.25} \mathrm{O}_{1.5}$ (method 1)

\begin{tabular}{|c|c|c|c|c|c|}
\hline $\begin{array}{l}L / L_{0} \\
(\%)\end{array}$ & $\begin{array}{l}I_{\mathrm{p}} / I_{\mathrm{s}} \\
(\%)\end{array}$ & $\begin{array}{l}I_{\mathrm{b} 1} / I_{\delta} \\
(\%)\end{array}$ & $\begin{array}{l}I_{c} / I_{\delta} \\
(\%)\end{array}$ & $\begin{array}{l}a_{\S}(\mathrm{nm}) \\
( \pm 0.0002 \mathrm{~nm})\end{array}$ & $\begin{array}{l}\text { Cationic composition } \\
\text { (at\%) }\end{array}$ \\
\hline 0 & 2000 & 220 & 4 & & $\begin{array}{l}{[\mathrm{La}]=33.3 ;[\mathrm{Sr}]=14.1 ;} \\
{[\mathrm{Co}]=47.5 ;[\mathrm{Bi}]=5.0 ;[\mathrm{Y}]<0.1}\end{array}$ \\
\hline 0.7 & 88 & 400 & 4 & & \\
\hline 1.1 & 11 & 45 & 3 & 0.5461 & \\
\hline 4.0 & - & 17 & 3 & 0.5459 & $\begin{array}{l}{[\mathrm{La}]=11.1 ;[\mathrm{Sr}]=2.7} \\
{[\mathrm{Co}]=18.7 ;[\mathrm{Bi}]=50.1:[\mathrm{Y}]=17.4}\end{array}$ \\
\hline 8.2 & - & 10 & $<2$ & 0.5459 & \\
\hline 15.0 & - & 9 & - & 0.5462 & \\
\hline 19.6 & - & 7 & - & 0.5466 & $\begin{array}{l}{[\mathrm{La}]=1.8 ;[\mathrm{Sr}]=0.4 ;} \\
{[\mathrm{Co}]=7.4 ;[\mathrm{Bi}]=67.7 ;[\mathrm{Y}]=22.7}\end{array}$ \\
\hline 42.0 & - & $<2$ & - & 0.5468 & \\
\hline 65 & - & - & - & 0.5473 & $\begin{array}{l}{[\mathrm{La}]=0 ;[\mathrm{Sr}]=0 ;} \\
{[\mathrm{Co}]=1.5 ;[\mathrm{Bi}]=73.9 ;[\mathrm{Y}]=24.6}\end{array}$ \\
\hline 95 & - & - & - & 0.5489 & \\
\hline
\end{tabular}

$L / L_{0}$ is the distance from the centre of the layer under investigation to the surface of electrode divided by the total thickness of the diffusion layer.

$I_{\mathrm{p}} / I_{s}, I_{\mathrm{h} 1} / I_{\delta}$ and $I_{\mathrm{c}} / I_{\delta}$ are the ratios of the intensities of $100 \%$-reflections of the phase with a perovskite structure, the phase with a $\mathrm{BiYO}$ structure and $\mathrm{Co}_{3} \mathrm{O}_{4}$ respectively, to intensity of $100 \%$-reflection of the phase $\delta$ - $\mathrm{BiO}_{1,9}$.

$a_{\delta}$ is the lattice parameter of the phase with the $\delta-\mathrm{BiO}_{1.5}$ structure. 
of hydrogen peroxide, over the solid electrolyte substrates heated to 870-900 K with subsequent sintering of the obtained layer during $2-3 \mathrm{~h}$ at 870 $\mathrm{K}$. Formation of a perovskite structure was verified by X-ray diffraction studies using powders scraped from the surfaces of the electrodes, and also by an indirect route (judging from the independence of the layer electrical conductivity from the duration of subsequent sintering). XFA was used for the control of electrode composition. Surface density $\left(d_{\mathrm{S}}\right)$ of the layers prepared by method 2 lies in the range 10 to $25 \mathrm{mg} \mathrm{cm}^{-2}$. The increase in substrate temperature to $950-970 \mathrm{~K}$ during dispersion leads to the increase in the resistance of the electrode layers, which is indicative of the interaction of electrode and electrolyte whereas the decrease in temperature to $840 \mathrm{~K}$ caused a substantial disimprovement in the reproducibility of the characteristics of the layers obtained. No evidence of interdiffusion of materials was detected, when this method was used at a substrate temperature of 870-900 K.

Studies of sheet resistance of the electrode layers on substrates $\mathrm{Bi}_{0.75} \mathrm{Y}_{0.25} \mathrm{O}_{1.5}$ and $\mathrm{Zr}_{0.90} \mathrm{Y}_{0.10} \mathrm{O}_{1.5}$ were conducted in the temperature range from 300 to $1100 \mathrm{~K}$ and at an oxygen partial pressure between $10^{-5}$ and $0.21 \times 10^{5} \mathrm{~Pa}$ using the 2-probe method at an alternating current $(5,10$ and $20 \mathrm{kHz})$ in the cells with platinum wires. $\mathrm{Bi}_{0.75} \mathrm{Y}_{0.25} \mathrm{O}_{1.5}$ and $\mathrm{Zr}_{0.90} \mathrm{Y}_{0.10} \mathrm{O}_{1.5}$ solid electrolyte substrates measuring $5 \times 2 \times 25 \mathrm{~mm}$ with the electrode applied on the largest of the sides were used for the investigations. Distinctions between the resistance values obtained by using alternating current of different frequencies were not greater than $2 \%$ of the measured value. Calculations were made by equation:

$\frac{\rho}{d}=\frac{R \times a}{l}$

where $p / d$ is the resistance parameter of electrode layers (ohm), $R$ is the measured resistance, $a$ is electrode width, $l$ is the distance between probes, $p$ is the specific electrical resistance of the porous electrode material, and $d$ is the effective thickness of the electrode investigated. The relative error of the determination of the parameter of electrode layer resistance was below $4 \%$ in the temperature range 600 to $1100 \mathrm{~K}$ and below $10 \%$ at a low temperature.

The polarization resistance measurements were carried out using a 3-probe scheme [12]. The procedure for the measurements has been described in Refs. $[8,13]$. In calculating the polarization resistance $\left(r_{\eta}\right.$, ohm $\left.\mathrm{cm}^{2}\right)$, we used the equations:

$r_{\eta}=S \times \frac{\mathrm{d} \eta}{\mathrm{d} I}$

$\eta=U-I R$,

where $\eta$ is the overpotential, $U$ is the total potential drop across the electrodes, $I R$ is the potential drop across the solid electrolyte, $I$ is the intensity of the current flowing through the cell, and $S$ is the area of the electrode investigated. The $R$ values were measured using alternating current $(10 \mathrm{kHz})$. This frequency was chosen empirically on the basis of the results of the investigations of the frequency dependence of electrochemical cell resistance as follows. Studies of the frequency dependence of conductivity have been carried out in a frequency range from $1 \times 10^{2}$ to $5 \times 10^{5} \mathrm{~Hz}$. In the frequency range 7 to 50 $\mathrm{kHz}$, resistance was independent of the frequency. This allowed us to reach the conclusion that resistance is determined solely by the conductivity of ceramics in this frequency range. Impedance associated with the electrochemical process emerges at lower frequencies. At higher frequencies resistance of grain boundaries and bulk grain resistance can be distinguished. Silver was used as a material for the counter-electrodes and reference electrodes. Polarization resistance was measured at temperatures from 773 to $973 \mathrm{~K}$ and oxygen partial pressure in the range from 0.5 to $2.1 \times 10^{4} \mathrm{~Pa}$ at the overpotential of $10 \mathrm{mV}$. Linear dependence of overpotential on current was observed, with a correlation coefficient of 0.999 . The relative error for the determination of polarization resistance was not above $5 \%$ with a significance level of $95 \%$.

\section{Results and discussion}

\subsection{The effect of the conditions of electrode preparation on the electrical conductivity of electrode layers}

XFA of $\operatorname{Ln}(\mathrm{Sr}) \mathrm{CoO}_{3-\delta}$ layers, prepared by method 1 , demonstrated the presence of bismuth oxide on 
electrode surfaces. Bismuth concentration on the surface of electrodes prepared by this method was from 3 to 7 at.\%. Thickness of the diffusion layers between electrode and electrolyte found from the investigations of the cross-sections of ceramic samples was of $0.3-0.5 \mathrm{~mm}$. X-ray diffraction studies demonstrated the retention of the perovskite structure of electrode materials at depths not above $2 \%$ of diffusion layers thickness (e.g. Table 2). The facecentered cubic (f.c.c.) structure of the solid electrolyte $\left(\delta-\mathrm{BiO}_{1.5}\right)$ was found across the whole depth of the layers. The phase of structure $\mathrm{Bi}_{0.5} \mathrm{Y}_{0.5} \mathrm{O}_{1.5}$ [14] was one of the main constituents of the diffusion layer. Values of interplanar distance corresponding to the most intensive reflections in X-ray patterns of this phase are $0.310,0.191$ and $0.270 \mathrm{~nm}$. Apparently, this phase is a solid solution of type $\mathrm{Bi}(\mathrm{Y}, \mathrm{La}, \mathrm{Sr}) \mathrm{O}_{1.5}$ formed as a result of lanthanum and strontium ion diffusion. Phase $\mathrm{Co}_{3} \mathrm{O}_{4}$ was also found in the diffusion layers. Values of the lattice parameter of the phase with a $\delta-\mathrm{BiO}_{1.5}$ structure at various distances from the surface of the diffusion layer $\left(a_{\delta}\right)$ are given in Table 2 . Changes in $a_{\delta}$ suggest the formation of solid solutions $\mathrm{Bi}(\mathrm{Y}, \mathrm{Co}) \mathrm{O}_{1.5}$ whose composition changes with the depth of interdiffusion of materials.

Thus, interaction between the materials of cobaltite electrode and $\mathrm{Bi}_{2} \mathrm{O}_{3}$-based electrolyte causes changes of chemical and phase composition of the materials used. Consequently, it is necessary to investigate properties of individual phases and also to elaborate the methods of applying of electrodes which prevent interaction of the materials.

No evidence of the interaction of solid electrolytes $\mathrm{Bi}_{0.75} \mathrm{Y}_{0.25} \mathrm{O}_{1.5}$ and $\mathrm{Zr}_{0.90} \mathrm{Y}_{0.10} \mathrm{O}_{1.5}$ with $\mathrm{Ln}_{1-x} \mathrm{Sr}_{x} \mathrm{CoO}_{3-\delta}$ electrodes prepared by method 2 were found. According to the results of XFA, deviations of the composition of the layers prepared by this procedure from stoichiometric composition were below $10 \%$ for the cations of $\mathrm{A}$ sublattice and below $3 \%$ for those of sublattice $\mathrm{B}$ of $\mathrm{ABO}_{3}$ perovskite. Such deviations from stoichiometry do not cause the disruption of the single-phase state of cobaltites. This was confirmed in the present work and conforms with the previously obtained data [15].

The procedure of electrode preparation strongly affects the electrical resistance of the electrode layers. For instance, interaction of cobaltites with
$\mathrm{ZrO}_{2}$-based solid electrolytes occurs far more slowly than with bismuth oxide-based ones at the sintering temperatures used (Table 1). The resistance of the electrode layers prepared by method 1 on $\mathrm{Bi}_{0.75} \mathrm{Y}_{0.25} \mathrm{O}_{1.5}$ substrates is $2-4$ times larger than that of layers having the same density on $\mathrm{Zr}_{0.90} \mathrm{Y}_{0.10} \mathrm{O}_{1.5}$ substrates. The implementation of method 2 enables electrode resistance to be decreased considerably (Fig. 1). The effect of the rise in substrate temperature above $920 \mathrm{~K}$ on nitrate dispersion caused the interaction of electrode materials, and also solid electrolyte, with $\mathrm{Bi}_{0.75} \mathrm{Y}_{0.25} \mathrm{O}_{1.5}$ and, consequently, the drop in electrical conductivity. Investigations of the dependence of the resistance parameter of $\mathrm{Ln}_{1-x} \mathrm{Sr}_{x} \mathrm{CoO}_{3-\delta}$ layers on oxygen partial pressure at different temperatures demonstrated that conductivity of the layers with a surface density below $30 \mathrm{mg} \mathrm{cm}^{-2}$ depends slightly on the oxygen content in the gas phase within all the investigated temperature range. The increase of the resistance parameter of electrode layers $\left(\frac{\Delta \rho}{d}\right)$ with oxygen pressure decrease becomes significant when $d_{\mathrm{S}}>35-40 \mathrm{mg} \mathrm{cm}^{-2}$ (Fig. 2).

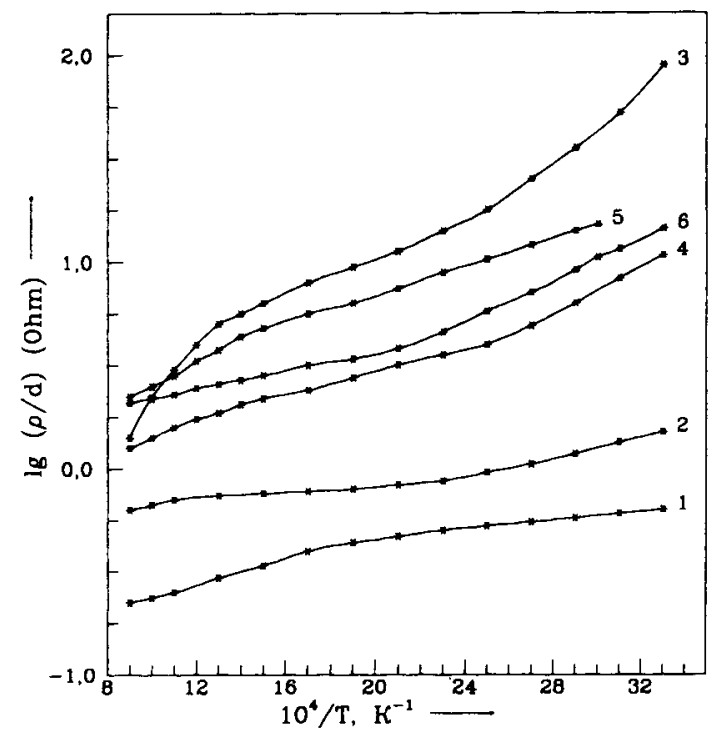

Fig. 1. Temperature dependence of the resistance parameter of $\mathrm{La}_{0,7} \mathrm{Sr}_{0,3} \mathrm{CoO}_{3-\delta}(1-5)$ and $\mathrm{Nd}_{0.5} \mathrm{Sr}_{0.5} \mathrm{CoO}_{3-8}$ (6) electrode layers with surface density of 51 (1), 47 (2), 24 (3), 21 (4), 20 (5) and $18(6) \mathrm{mg} \mathrm{cm}^{-2}$ prepared by method $1(1-3)$ and by method 2 at temperatures of $870-900 \mathrm{~K}(4,6)$ and $950-970 \mathrm{~K}(5)$ on solid electrolyte substrates $\mathrm{Zr}_{0.9} \mathrm{Y}_{0.1} \mathrm{O}_{1.95}$ (1) and $\mathrm{Bi}_{0,75} \mathrm{Y}_{0,25} \mathrm{O}_{0.15}$ (2-6). 


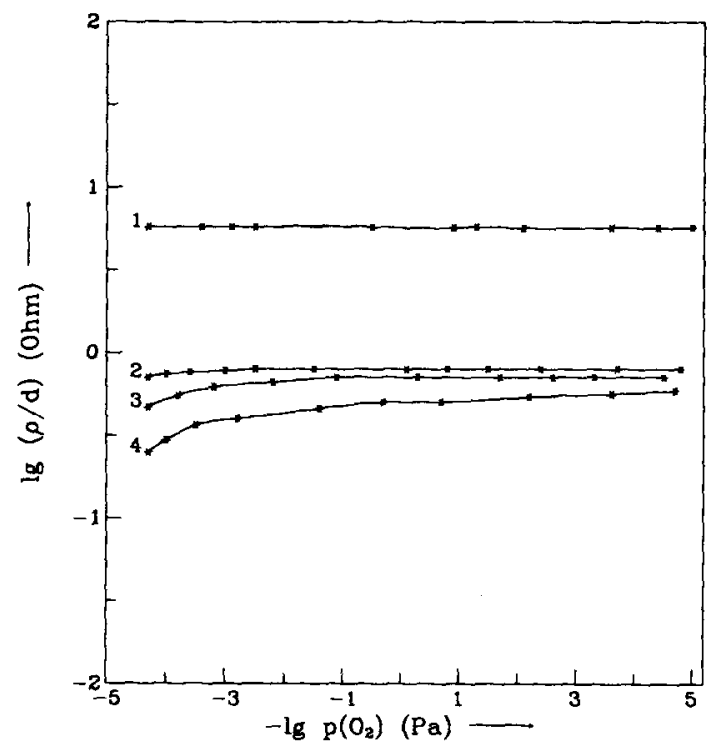

Fig. 2. The resistance parameter of $\mathrm{Nd}_{0,5} \mathrm{Sr}_{0.5} \mathrm{CoO}_{3-8}$ electrode layers with surface density of 24 (curve 1); 41 (2); 56 (3); 66 $\mathrm{mg} \mathrm{cm}{ }^{-2}$ (4) on $\mathrm{Zr}_{6.9} \mathrm{Y}_{0.1} \mathrm{O}_{0.195}$ solid electrolyte substrates as a function of oxygen partial pressure at $1010 \pm 3 \mathrm{~K}$.

\subsection{The properties of the phases incorporated to the diffusion layers between electrodes and electrolyte}

\subsection{1. $\mathrm{La}(\mathrm{Sr}, \mathrm{Bi}) \mathrm{CoO}_{3-\delta}$ solid solutions}

Polycrystalline samples $\mathrm{La}_{1-x-y} \mathrm{Sr}_{x} \mathrm{Bi}_{y} \mathrm{CoO}_{3-\delta}$ $(x=0-0.5 ; y=0-0.20)$ were synthesized to study the influence of the substitution of REE and strontium cations by bismuth on the properties of $\mathrm{Ln}_{1-x} \mathrm{Sr}_{x} \mathrm{CoO}_{3-\delta}$. The powders of Bi-doped cobaltites were synthesized from the corresponding nitrates at $1370-1450 \mathrm{~K}$ in air for $25-30 \mathrm{~h}$ with repeated intervening grindings. The XFA of $\mathrm{La}_{1-x-y} \mathrm{Sr}_{x} \mathrm{Bi}_{y} \mathrm{CoO}_{3-\delta}$ demonstrated that no evaporation of bismuth oxide was observed for specimens with small bismuth content, in spite of high sintering temperature: deviations of bismuth content from stoichiometric composition did not exceed $3 \%$ at $y=0-0.10$. With increasing $y$ the buildup of the cationic non-stoichiometry of ceramic samples was observed. From $\mathrm{X}$-ray diffraction studies of $\mathrm{La}_{1-x-x} \mathrm{Sr}_{x} \mathrm{Bi}_{y} \mathrm{CoO}_{3-\delta}$, the range of bismuth concentrations in which the solid solutions with perovskite structure are formed is very narrow. It corre- sponds to $y$ values of $0-0.05$ in all the investigated $x$ range from 0 to 0.50 . Traces of the $\delta$-phase of bismuth oxide were found with $y=0.10$. Partial decomposition of the perovskite structure was observed to yield $\delta-\mathrm{BiO}_{1.5}$ and $\mathrm{Co}_{3} \mathrm{O}_{4}$. $\mathrm{La}(\mathrm{Sr}, \mathrm{Bi}) \mathrm{CoO}_{3-\delta}$ solid solutions have a perovskite structure with rhombohedral distortion which is inherent for lanthanum cobaltite. Crystal lattice parameters of $\mathrm{La}(\mathrm{Sr}, \mathrm{Bi}) \mathrm{CoO}_{3-\delta}$ are given in Table 3. Lowering of the temperature at which the liquid phase appears was observed with the buildup of bismuth concentration.

The temperature dependence of $\mathrm{La}_{1-x-y} \mathrm{Sr}_{x} \mathrm{Bi}_{y} \mathrm{CoO}_{3-\delta}$ electrical conductivity is presented in Fig. 3. The decrease of conductivity with increasing $y$ is due both to the lowering of the overlap integral of the d-orbitals of cobalt cations and $p_{\pi}$-orbitals of anions because of the decline in the mean radius of the cations of the A sublattice [16] and to partial decomposition of perovskite to yield the $\delta$ - $\mathrm{BiO}_{1.5}$-based phase, which has lower conductivity. For specimens with $x \geq 0.2$ (plots 3-8), replacement of lanthanum for bismuth causes a change in the form of the temperature dependence of electrical conductivity. The solid solutions with $y=0$ and $x \geq 0.2$ are characterized by metallic conductivity over all the investigated temperature range, whereas at $y \geq 0.05$ the temperature of the transition to metallic conductivity lies in the range 450 to $750 \mathrm{~K}$. The exceptions are the compositions with $x=0.5$ (plots 5,8 ) the resistance temperature coefficient of

Table 3

The properties of $\mathrm{La}_{1-x-} \mathrm{Sr}_{4} \mathrm{Bi}_{4} \mathrm{CoO}_{3-\delta}$ ceramics

\begin{tabular}{|c|c|c|c|c|}
\hline \multirow[t]{2}{*}{$x$} & \multirow[t]{2}{*}{$y$} & \multicolumn{2}{|c|}{ Parameter of unit cell } & \multirow{2}{*}{$\begin{array}{l}d_{\mathrm{cxp}} \\
\left(\mathrm{kg} \mathrm{m}^{-3}\right.\end{array}$} \\
\hline & & $a(\mathrm{~nm})$ & $\alpha\left({ }^{\circ}\right)$ & \\
\hline 0 & 0 & 0.5388 & 60.80 & 6100 \\
\hline 0.20 & 0 & 0.5407 & 60.56 & 5840 \\
\hline 0.35 & 0 & 0.4512 & 60.38 & 5630 \\
\hline 0.50 & 0 & 0.5418 & 60.24 & 5360 \\
\hline 0.20 & 0.05 & 0.5398 & 60.59 & 5900 \\
\hline 0.35 & 0.05 & 0.5401 & 60.51 & 5740 \\
\hline 0.50 & 0.05 & 0.5410 & 60.17 & 5450 \\
\hline 0 & 0.10 & 0.5379 & 60.81 & 6230 \\
\hline 0.20 & 0.10 & 0.5398 & 60.59 & 5930 \\
\hline 0.35 & 0.10 & 0.5406 & 60.48 & 5780 \\
\hline 0.50 & 0.10 & 0.5405 & 60.39 & 5510 \\
\hline
\end{tabular}

${ }^{a} d_{\text {c } \times P}$ is the density of ceramics. 


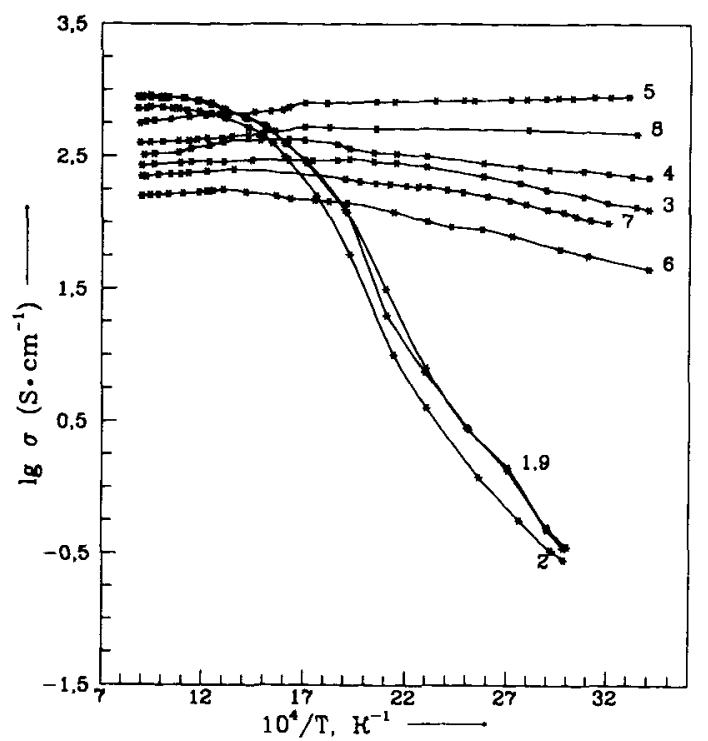

Fig. 3. Electrical conductivity vs. temperature plot for the specimens of $\mathrm{La}_{1-x+y} \mathrm{Sr}_{x} \mathrm{Bi}_{y} \mathrm{CoO}_{3-\delta}$ with $(x=0 ; y=0.05)(1) ;(x=0$; $y=0.10)(2) ;(x=0.20 ; y=0.05)(3) ;(x=0.35 ; y=0.05)$ (4); $(x=0.50 ; y=0.05)(5) ;(x=0.20 ; y=0.10)(6) ;(x=0.35 ; y=$ $0.10)(7) ;(x=0.50 ; y=0.10)(8) ;(x=0 ; y=0)(9)$

which declines from $(10.3 \pm 0.3) \times 10^{-4} \mathrm{~K}^{-1}$ for $\mathrm{La}_{0.5} \mathrm{Sr}_{0.5} \mathrm{CoO}_{3-\delta}$ [17] to $(2.1 \pm 0.3) \times 10^{-4} \mathrm{~K}^{-1}$ for $\mathrm{La}_{0.45} \mathrm{Sr}_{0.50} \mathrm{Bi}_{0.05} \mathrm{CoO}_{3-\delta}$.

The average values of the thermal expansion coefficients (TEC) of $\mathrm{La}_{1-x-y} \mathrm{Sr}_{x} \mathrm{Bi}_{y} \mathrm{CoO}_{3-\delta}$ samples at $y=0-0.10$ calculated from the results of dilatometric investigations are almost independent of bismuth concentration and are consistent with the thermal expansion coefficients of $\mathrm{La}_{1-x} \mathrm{Sr}_{x} \mathrm{CoO}_{3-\delta}$ solid solutions.

Oxygen permeability of cobaltites decreases 8 to 10 times with the replacement of $10 \%$ of lanthanum by bismuth (Table 4 ). The lowering of the parame-

Table 4

The values of oxygen permeability of $\mathrm{La}_{1-y} \mathrm{Bi}_{3} \mathrm{CoO}_{3-s}$ ceramic samples averaged over the oxygen partial pressure range from $0.21 \times 10^{5}$ to $5 \times 10^{3} \mathrm{~Pa}$

\begin{tabular}{llll}
\hline$y$ & $\bar{J}\left(\mathrm{O}_{2}\right) \times 10^{8}\left(\mathrm{~mol} \mathrm{~s}^{-1} \mathrm{~cm}^{-1}\right)$ & \\
\cline { 2 - 4 } & $1115 \mathrm{~K}$ & $1175 \mathrm{~K}$ & $1240 \mathrm{~K}$ \\
\hline 0 & 3.63 & 4.07 & 4.68 \\
0.05 & 0.62 & 0.98 & 1.35 \\
0.10 & 0.22 & 0.28 & 0.48 \\
\hline
\end{tabular}

ters of oxygen ion transfer with increasing $y$ can be explained by the strengthening of interaction of anions with the ions of sublattice $A$ due to the decrease in the mean radius of the cations of this sublattice.

Thus, substitution of lanthanum and strontium with bismuth results in the fall in electrical conductivity and oxygen permeability of cobaltites, suggesting that it is necessary to minimize the interaction of cobaltites and bismuth oxide-based solid electrolytes on the application of electrodes.

\subsubsection{The complex oxides of the system $\mathrm{BiO}_{1.5}$ $\mathrm{YO}_{1.5}-\mathrm{CoO}_{1.33}$}

Investigations of the complex oxides of systems $\mathrm{BiO}_{1.5}-\mathrm{CoO}_{1.33}$ and $\mathrm{BiO}_{1.5}-\mathrm{YO}_{1.5}-\mathrm{CoO}_{1.33}$ were aimed at the study of the influence of cobalt oxide addition on physico-chemical properties of the solid electrolytes based on bismuth oxide stabilized by yttrium. The formation of such complex oxides is likely in the superficial surface layers of solid electrolyte substrates, through cobalt diffusion (see Table 2).

Polycrystalline $\left(\mathrm{Bi}_{1-r} \mathrm{Co}_{x}\right)_{1-r} \mathrm{Y}_{v} \mathrm{O}_{1.5}$ samples $(x=$ $0-0.80 ; \quad y=0-0.25)$ were synthesized from $\mathrm{Y}\left(\mathrm{NO}_{3}\right)_{3} \cdot 6 \mathrm{H}_{2} \mathrm{O}$ and $\mathrm{Bi}_{1-x} \mathrm{Co}_{x} \mathrm{O}_{1.5}$ powders of corresponding composition prepared by sintering in air at $850-1000 \mathrm{~K}$ during $20-60 \mathrm{~h}$. The synthesis of $\left(\mathrm{Bi}_{1-x} \mathrm{Co}_{x}\right)_{1-y} \mathrm{Y}_{y} \mathrm{O}_{1.5}$ was conducted at $900-1200 \mathrm{~K}$ for $10-25 \mathrm{~h}$.

The X-ray diffraction studies of the specimens of the $\mathrm{BiO}_{1.5}-\mathrm{CoO}_{1.33}$ system showed the stabilization of the b.c.c. phase which is isostructural to $\gamma-\mathrm{BiO}_{1.5}$ (so called $\gamma^{*}-\mathrm{BiO}_{1.5}[18]$ ). The minimum concentration of $\mathrm{CoO}_{1.33}$ necessary for the stabilization of the $\gamma^{*}$-phase is $4 \pm 1 \mathrm{~mol} \%$ which corresponds to 1 cobalt atom per unit cell of $\gamma^{*}-\mathrm{BiO}_{1.5}$. The change of the lattice parameter of $\gamma^{*}$-phase when the cobalt oxide content changes in the range 4 to $7 \mathrm{~mol} . \%$ with retention of the single-phase state is indicative of the formation of the narrow composition range of solid solutions. The obtained results agree with the data on the $\mathrm{Bi}_{25} \mathrm{CoO}_{40}$ phase [19].

The composition range with lower cobalt oxide content was not single-phase. In addition to $\gamma^{*}$ $\mathrm{BiO}_{1.5}, \alpha-\mathrm{BiO}_{1.5}$ (in which solubility of cobalt oxide is low) or tetragonal $\beta^{*}$-biO ${ }_{1.5}$ was found. In the composition range with cobalt oxide content above 
$10 \%, \gamma^{*}-\mathrm{BiO}_{1.5}$ and $\mathrm{CoO}_{1.33}$ phases were found in all the investigated range of compositions. The quantity of $\mathrm{CoO}_{1.33}$ estimated from the intensity of $100 \%$ peaks of the corresponding phases increases in $\mathrm{Bi}_{1-x} \mathrm{Co}_{x} \mathrm{O}_{1.5}$ ceramic specimens with increasing $x$. The stability of phase composition in the $\mathrm{BiO}_{1.5}$ $\mathrm{CoO}_{1.33}$ system is confirmed by high-temperature $X$-ray diffraction studies, differential thermal analysis (DTA) and by the constancy of phase composition with the change of conditions of synthesis. The values of the parameters of $\gamma^{*}-\mathrm{BiO}_{1.5}$ unit cell of $\mathrm{Bi}_{1-x} \mathrm{Co}_{x} \mathrm{O} 1.5$ are given in Table 5 .

DTA demonstrated the existence of an endothermic effect in the system $\mathrm{BiO}_{1.5}-\mathrm{CoO}_{1.33}$ at $1005 \pm 4$ $\mathrm{K}$, the magnitude of which decreases with an increase in the quantity of cobalt oxide. The temperature of this effect coincides with the temperature of the phase transition $\alpha \rightarrow \delta$, which is characteristic for bismuth oxide [20]. However, high-temperature Xray diffraction studies demonstrated the retention of the b.c.c. structure up to the melting of the specimens. Such a change in $\mathrm{Bi}_{1-x} \mathrm{Co}_{x} \mathrm{O}_{1.5}$ properties suggests the disordering of the bismuth oxide anionic sublattice at $1005 \pm 5 \mathrm{~K}$, probably in association with the change of the properties of the $\mathrm{Bi}^{3+}$-oxygen ion bond.

The results of the investigations of the electrical

Table 5

The properties of $\left(\mathrm{Bi}_{1-x} \mathrm{Co}_{x}\right)_{1-y} \mathrm{Y}_{y} \mathrm{O}_{1.5}$ ceramics

\begin{tabular}{|c|c|c|c|c|c|}
\hline \multirow[t]{2}{*}{$y$} & \multirow[t]{2}{*}{$x$} & \multirow[t]{2}{*}{ Structure } & \multirow[t]{2}{*}{$a(\mathrm{~nm})$} & \multicolumn{2}{|l|}{ TEC $^{a}$} \\
\hline & & & & $T(\mathrm{~K})$ & $\alpha \times 10^{-6}\left(\mathrm{~K}^{-1}\right)$ \\
\hline \multirow[t]{6}{*}{0} & 0.05 & b.c.c. & 1.0163 & $300-940$ & 16.1 \\
\hline & 0.10 & & 1.0188 & $300-940$ & 15.6 \\
\hline & 0.20 & & 1.0186 & $300-940$ & 14.6 \\
\hline & 0.30 & & 1.0185 & $300-940$ & 14.2 \\
\hline & 0.40 & & 1.0185 & $300-880$ & 12.2 \\
\hline & 0.50 & & 1.0185 & $300-960$ & 11.3 \\
\hline \multirow[t]{10}{*}{0.10} & 0.10 & f.c.c. & 0.5512 & $550-1100$ & 19.3 \\
\hline & 0.20 & & 0.5521 & $600-800$ & 18.4 \\
\hline & & & & $850-1100$ & 24.5 \\
\hline & 0.30 & & 0.5527 & $400-650$ & 14.0 \\
\hline & & & & $650-1000$ & 20.9 \\
\hline & 0.40 & & 0.5520 & $500-1000$ & 16.3 \\
\hline & 0.50 & & 0.5512 & $300-600$ & 10.9 \\
\hline & & & & $650-1050$ & 17.6 \\
\hline & 0.60 & & 0.5506 & $600-1000$ & 16.2 \\
\hline & 0.70 & & 0.5485 & $600-1000$ & 15.6 \\
\hline
\end{tabular}

'TEC $(\alpha)$ is the mean value of the thermal expansion coefficient.

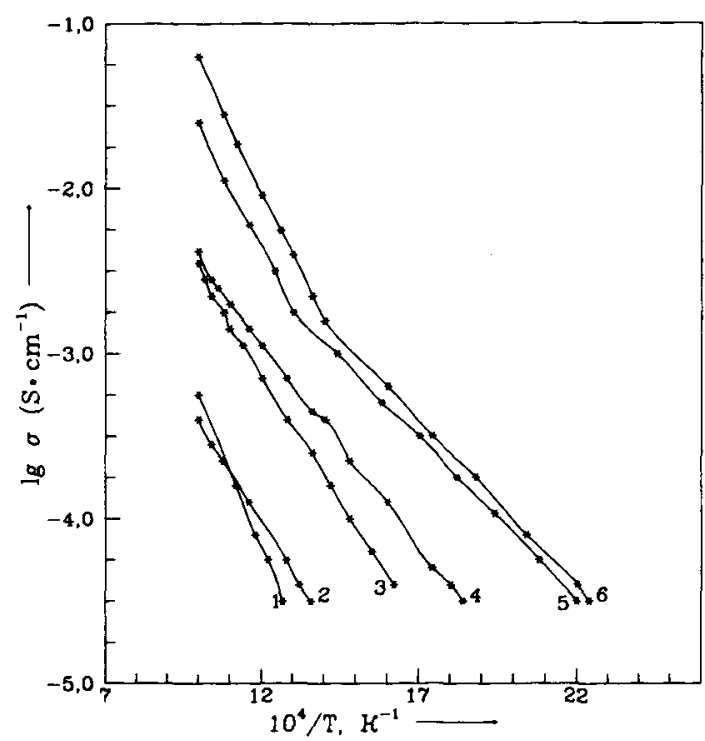

Fig. 4. Temperature dependence of electrical conductivity of the ceramic samples $\mathrm{Bi}_{1-x} \mathrm{Co}_{3} \mathrm{O}_{1.5}$ with $x=0.05$ (1); 0.10 (2); 0.20 (3); $0.30(4) ; 0.40(5) ; 0.50(6)$.

conductivity of $\mathrm{Bi}_{1-x} \mathrm{Co}_{x} \mathrm{O}_{15}$ specimens are presented in Fig. 4. At temperatures below $900 \mathrm{~K}$, the conductivity of all investigated compositions is predominantly electronic. The electrical conductivity of non-single-phase compositions is determined by the quantity of the more conductive phase $\mathrm{CoO}_{1,33}$. Oxygen ion transference numbers rise steeply at temperatures above $970 \mathrm{~K}$ reaching $0.60 \pm 0.08$ for $\mathrm{Bi}_{0.95} \mathrm{Co}_{0.05} \mathrm{O}_{1.5}$ specimens at $1040 \mathrm{~K}$. The sharp increase of ionic oxide conductivity near $1000 \mathrm{~K}$ confirms the disordering of the anionic sublattice of bismuth oxide.

The doping by yttrium oxide offers stabilization of the f.c.c. phase which is isostructural to $\delta-\mathrm{BiO}_{1.5}$ ( $\delta^{*}$-phase of bismuth oxide [18]) in system $\mathrm{BiO}_{1.5}$ $\mathrm{YO}_{1.5}-\mathrm{CoO}_{1.33}$. The minimum concentration of yttria doping additive which is necessary to turn the $\gamma^{*}$-phase of $\mathrm{Bi}_{1-x} \mathrm{Co}_{x} \mathrm{O}_{1.5}$ to the $\delta^{*}$-phase is well below the quantity necessary for the complete stabilization of monoclinic $\alpha-\mathrm{BiO}_{1.5}(\sim 23 \mathrm{~mol} . \%)$. When the content of the additives (cobalt and yttrium oxides) is somewhat below the limit of $\delta^{*}$-phase stabilization, $\gamma^{*}-\mathrm{BiO}_{1.5}$ remains in the system, whereas with a lower additive content, the tetragonal $\beta^{*}$-phase remains (Fig. 5).

The typical temperature dependence of the electri- 


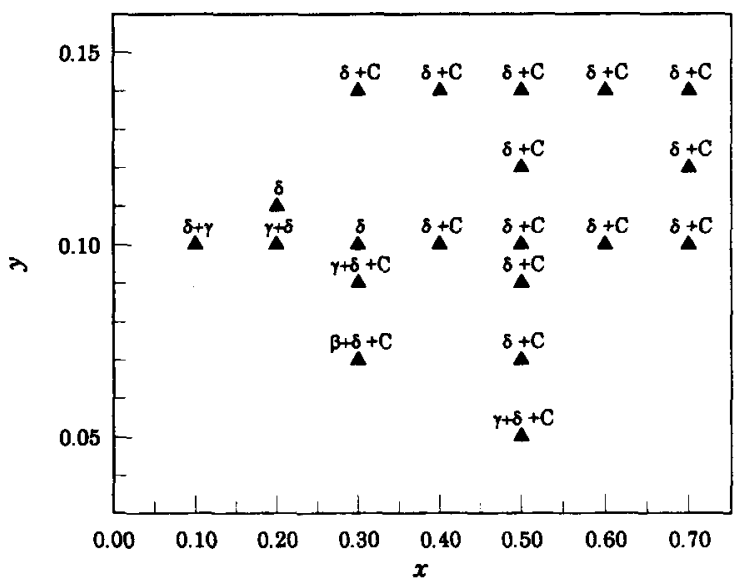

Fig. 5. Phase composition of the samples of the $\left(\mathrm{Bi}_{1-1} \mathrm{Co}_{x}\right)_{1-9}, \mathrm{Y}_{y} \mathrm{O}_{1.5}$ system at room temperature: $\boldsymbol{\beta}-\boldsymbol{\beta}^{*}-\mathrm{BiO}_{1.5}$, $\gamma-\gamma^{*}-\mathrm{BiO}_{1.5}, \delta-\delta^{*}-\mathrm{BiO}_{1.5}, \mathrm{C}-\mathrm{CoO}{ }_{1.333}$.

cal conductivity for the $\left(\mathrm{Bi}_{1-x} \mathrm{Co}_{x}\right)_{1-y} \mathrm{Y}_{y} \mathrm{O}_{1.5}$ system is plotted in Fig. 6. The electrical conductivity in the temperature range $300-750 \mathrm{~K}$ is proportional to $\mathrm{CoO}_{1.33}$ concentration. The break in the conductivity curves at $750-850 \mathrm{~K}$ is probably caused by activation of oxygen ion transfer.

The concentration dependence of

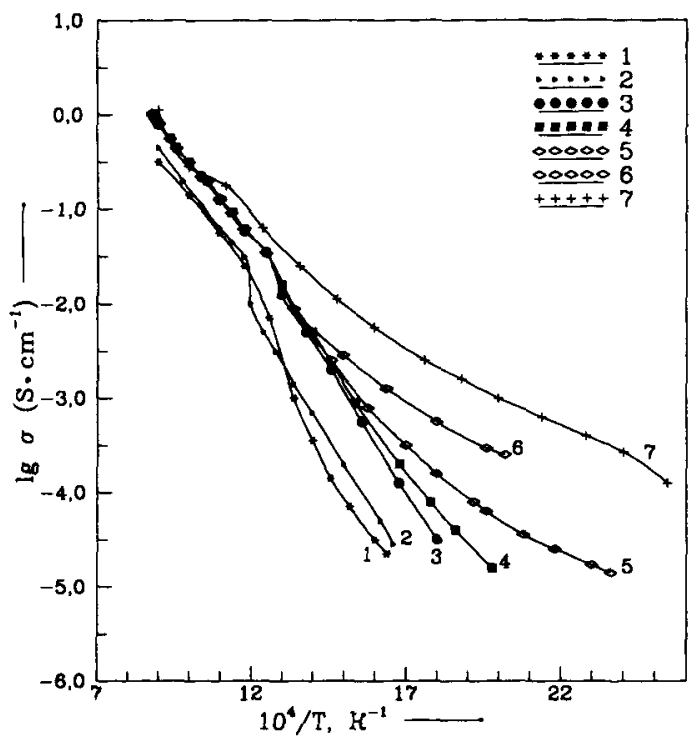

Fig. 6. Temperature dependence of electrical conductivity of $\left(\mathrm{Bi}_{1-x} \mathrm{Co}_{x}\right)_{1-,} \mathrm{Y}_{1} \mathrm{O}_{1.5}$ ceramics with $x=0.10(1) ; 0.20(2) ; 0.30$ (3); $0.40(4) ; 0.50(5) ; 0.60(6) ; 0.70(7)$.
$\left(\mathrm{Bi}_{1-x} \mathrm{Co}_{x}\right)_{1-y} \mathrm{Y}_{y} \mathrm{O}_{1.5}$ ionic oxygen conductivity (Table 5) calculated from the results of the measurements of electrical conductivity and ion transference numbers corresponds to the change of the parameter of the f.c.c. structure of the solid solutions of the triple oxide system. The maximum ionic oxygen conductivity is reached at the point of $\delta^{*}-\mathrm{BiO}_{1.5}$ stabilization. This conforms well both to the notion that conductivity of solid solutions with a f.c.c. structure has a linear relationship with lattice parameter (i.e. is determined by the size of the channels of oxygen ion transfer) and the notion that electrical conductivity of bismuth oxide-based solid solutions becomes smaller with an increase in the content of the stabilizing additive because of the stronger bond of the cations of the additive with oxygen anions [21]. The ratio of bismuth and yttrium concentrations determines the change of lattice parameter and ionic conductivity. A regular increase in electronic conductivity with increasing $x$ takes place in $\left(\mathrm{Bi}_{1-x} \mathrm{Co}_{x}\right)_{1-\gamma} \mathrm{Y}_{,} \mathrm{O}_{1.5}$ system.

The values of $\left(\mathrm{Bi}_{1-x} \mathrm{Co}_{x}\right)_{1-y}, \mathrm{Y}_{y} \mathrm{O}_{1.5}$ oxygen permeability (Table 6) were calculated using the results of the measurements of electrical conductivity and transfer numbers from the equation [22]:

$J\left(\mathrm{O}_{2}\right)=\frac{R T}{16 F^{2}} \cdot t_{\mathrm{O}}\left(1-t_{\mathrm{O}}\right) \cdot \bar{\sigma}$

where $t_{\mathrm{O}}$ is the oxygen ion transference number, $\bar{\sigma}$ is the mean value of the total conductivity at a given difference of oxygen partial pressure at both sides of specimens $\left(1.01 \times 10^{5}\right.$ and $\left.0.21 \times 10^{5} \mathrm{~Pa}\right) . J\left(\mathrm{O}_{2}\right)$ is the coefficient of proportionality between oxygen permeation flux via ceramics and difference in

Table 6

The transfer parameters in $\left(\mathrm{Bi}_{1-x} \mathrm{CO}_{x}\right)_{1-x} \mathrm{Y}, O_{1.5}$ at $1050 \mathrm{~K}$

\begin{tabular}{llll}
\hline$x$ & $\begin{array}{l}\sigma_{\mathrm{O}} \\
\left(\mathrm{S} \mathrm{cm}^{-1}\right)\end{array}$ & $\begin{array}{l}\sigma_{\mathrm{c}} \\
\left(\mathrm{S} \mathrm{cm}^{-1}\right)\end{array}$ & $\begin{array}{l}\bar{J}\left(\mathrm{O}_{2}\right) \times 10^{9} \\
\left(\mathrm{~mol} \mathrm{~s}^{-1} \mathrm{~cm}^{-1}\right)\end{array}$ \\
\hline 0.20 & 0.27 & 0.01 & 0.63 \\
0.30 & 0.41 & 0.09 & 4.1 \\
0.40 & 0.38 & 0.18 & 7.2 \\
0.50 & 0.36 & 0.20 & 7.5 \\
0.60 & 0.31 & 0.25 & 13.0 \\
0.70 & 0.26 & 0.53 & 10.0 \\
\hline
\end{tabular}

$\sigma_{\circ}$ and $\sigma_{\mathrm{c}}$ are the values of ionic oxygen and electronic conductivity calculated from the measurements of total electrical conductivity and transference numbers. 
oxygen chemical potential at the different sides of the specimen under investigation [22]:

$J\left(\mathrm{O}_{2}\right)=\frac{R T D}{4 F} \cdot \frac{j}{E}$

where $j\left(\mathrm{~mol} \mathrm{~s}^{-1} \mathrm{~cm}^{-2}\right)$ is the flux of oxygen, passing through the ceramic sample under investigation, $D$ is the sample thickness, $E$ is the e.m.f. of electrochemical oxygen sensor. The values of $E$ are given by the formula:

$E=\frac{R T}{4 F} \cdot \ln \left(p_{2} / p_{1}\right)$,

where $p_{1}$ and $p_{2}$ are the oxygen partial pressure values at the different sides of the ceramics. Maximum oxygen permeability in the $\left(\mathrm{Bi}_{1-x} \mathrm{Co}_{x}\right)_{1-y} \mathrm{Y}_{y} \mathrm{O}_{1.5}$ system corresponds to $x=$ $0.60 \div 0.70 ; y=0.07 \div 0.15$ (Table 6).Thus, the complex oxides of the $\mathrm{BiO}_{1.5}-\mathrm{YO}_{1.5}-\mathrm{CoO}_{1.33}$ triple system have a reasonably high ionic oxygen conductivity (the values are comparable with those for REE cobaltites and bismuth oxide-based solid electrolytes).

\subsection{The polarization resistance of electrode layers}

Insofar as method 2 makes it possible to obtain the electrode layers with well-developed surfaces (Fig. 7) and provides minimum interaction of materials, studies of electrode polarization resistance were conducted mainly for the electrode layers obtained by nitrate spray-coating. Only specimens of electrode layers for which dispersion of reproducibility of the resistance parameter $(\rho / d)$ was below $3 \%$ of the value in the temperature range 773 to $973 \mathrm{~K}$ were used for investigations. The discrepancy in the values of polarization resistance of electrodes of the same composition obtained by method 2 was no more than $10 \%$.

In Figs. 8 and 9 the dependencies of the polarization resistance of the electrode layers, prepared by method 2 on $\mathrm{Bi}_{0.75} \mathrm{Y}_{0.25} \mathrm{O}_{1.5}$ solid electrolyte substrates, on temperature in air and on oxygen partial pressure at $870 \mathrm{~K}$ in the regime of cathodic polarization are presented. The data for the silver electrode are given for comparison. The polarization resistance of the $\mathrm{La}_{0.7} \mathrm{Sr}_{0.3} \mathrm{CoO}_{3-\delta}$ electrode is below that of the silver electrode over all the ranges of temperature

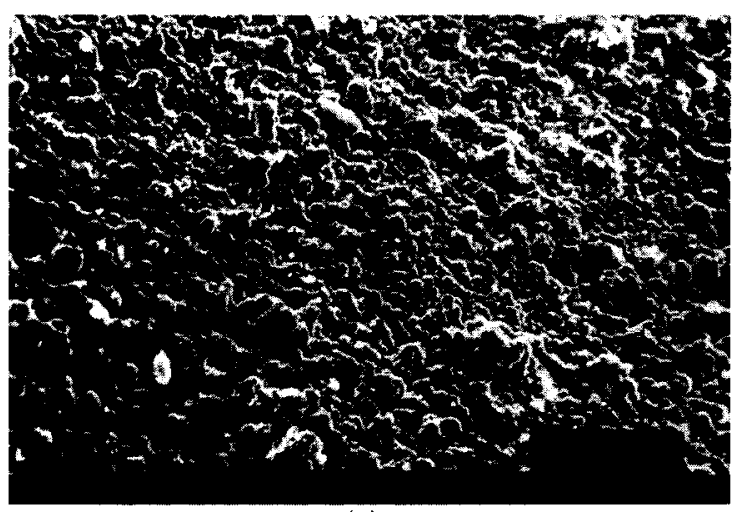

(a)

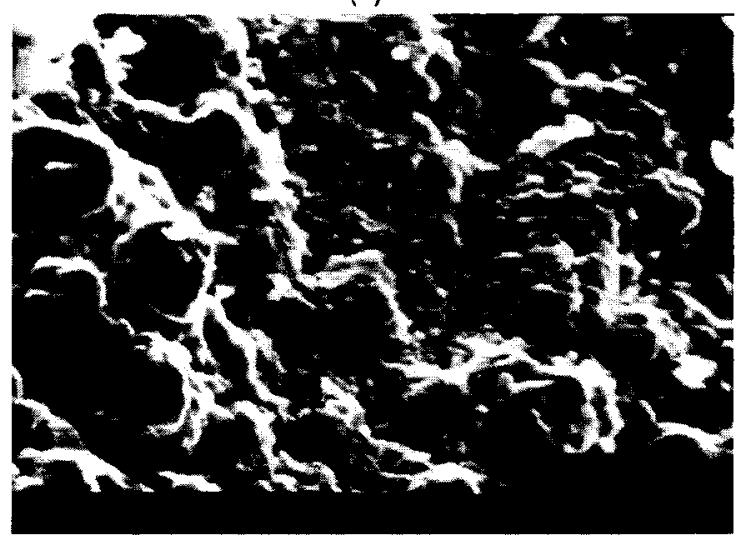

(b)

Fig. 7. Surface of $\mathrm{La}_{0.7} \mathrm{Sr}_{0.3} \mathrm{CoO}_{3-\delta}$ electrode prepared by method 2. The micrographs were taken with a Nanolab-7 scanning electron microscope.

and oxygen partial pressures studied. The $\mathrm{Pr}_{0.5} \mathrm{Sr}_{0.5} \mathrm{CoO}_{3-\delta}$ electrode has good characteristics at temperatures below $770 \mathrm{~K}$ in air. Its polarization resistance is below the corresponding values for the silver electrode at $T<850 \mathrm{~K}$ and for the $\mathrm{La}_{0.7} \mathrm{Sr}_{0.3} \mathrm{CoO}_{3-\delta}$ electrode at $T<750 \mathrm{~K}$. The results obtained differ from the data of [6]. This can be due to the differences in electrode preparation conditions which can affect not only the porosity and microstructure of electrode layers but also the physicochemical properties of the materials used. The analysis of the dependence of the $\mathrm{Ln}_{1-x} \mathrm{Sr}_{x} \mathrm{CoO}_{3-\delta}$ electrode polarization resistance on oxygen partial pressure (Fig. 9) leads to the conclusion that several factors which limit the rate of electrochemical reaction are combined $[12,23]$. For $\mathrm{Nd}_{0.5} \mathrm{Sr}_{0.5} \mathrm{CoO}_{3-\delta}$ the dependence of polarization resistance on $p\left(\mathrm{O}_{2}\right)$ 


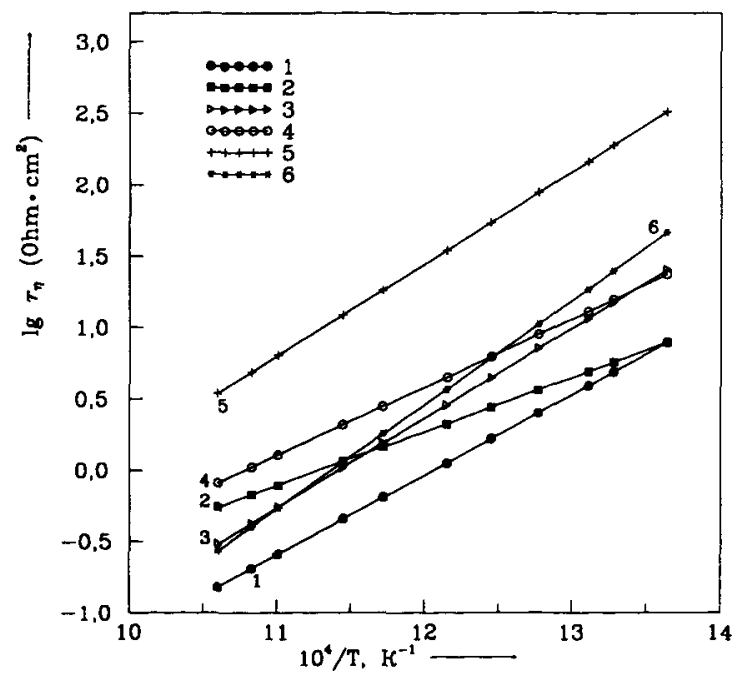

Fig. 8. Polarization resistance vs. temperature plot in the regime of cathodic polarization in air for electrodes $\mathrm{La}_{0.7} \mathrm{Sr}_{0.3} \mathrm{CoO}_{3-8}$ (1), $\mathrm{Pr}_{0.5} \mathrm{Sr}_{0.5} \mathrm{CoO}_{3-8}$ (2), $\mathrm{Nd}_{0.5} \mathrm{Sr}_{0.5} \mathrm{CoO}_{3-\delta}(3), \mathrm{SrCo}_{0.5} \mathrm{Fe}_{0.5} \mathrm{O}_{3-\delta}$ (4), $\mathrm{Bi}_{0.27} \mathrm{Co}_{0.63} \mathrm{Y}_{0.1} \mathrm{O}_{1.5}(5), \mathrm{Ag}(6)$ on $\mathrm{Bi}_{0.75} \mathrm{Y}_{0.25} \mathrm{O}_{1.5}$ solid electrolyte substrates. Electrodes $\mathrm{Ln}(\mathrm{Sr}) \mathrm{CoO}_{3-5}$ and $\mathrm{SrCo}_{0.5} \mathrm{Fe}_{0.5} \mathrm{O}_{3-\delta}$ were prepared by method 2. The electrode $\mathrm{Bi}_{0.27} \mathrm{Co}_{0.63} \mathrm{Y}_{0.1} \mathrm{O}_{1.5}$ and the silver electrode were prepared by method 1 .

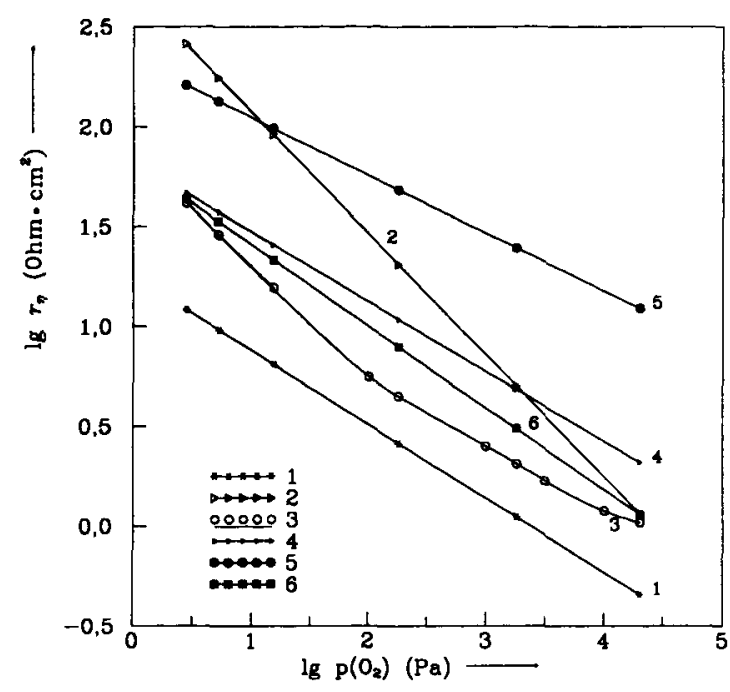

Fig. 9. Polarization resistance as a function of oxygen partial pressure in the regime of cathodic polarization at $870 \mathrm{~K}$ for electrodes $\mathrm{La}_{0.7} \mathrm{Sr}_{0.3} \mathrm{CoO}_{3-8}$ (1), $\mathrm{Pr}_{0.5} \mathrm{Sr}_{0.5} \mathrm{CoO}_{3-8}$ (2), $\mathrm{Nd}_{0.5}$ (3), $\mathrm{SrCo}_{0.5} \mathrm{Fe}_{0.5} \mathrm{O}_{3-8}$ (4), $\mathrm{Bi}_{0.27} \mathrm{Co}_{0.63} \mathrm{Y}_{0.1} \mathrm{O}_{1.5} \quad$ (5), $\mathrm{Ag}$ (6) on $\mathrm{Bi}_{0.75} \mathrm{Y}_{0.25} \mathrm{O}_{1.5}$ solid electrolyte substrates. Electrodes $\mathrm{Ln}(\mathrm{Sr}) \mathrm{CoO}_{3-8}$ and $\mathrm{SrCo}_{0.5} \mathrm{Fe}_{0,5} \mathrm{O}_{3-\delta}$ were prepared by method 2 . The electrode $\mathrm{Br}_{0.2}, \mathrm{Co}_{0.63} \mathrm{Y}_{0.1} \mathrm{O}_{1.5}$ and the silver electrode were prepared by method 1 . has a break between $1.5 \times 10^{2}$ and $9.0 \times 10^{2} \mathrm{~Pa}$ (in the investigated temperature range). The location of this break shifts towards higher oxygen partial pressures with increasing temperature.

It is noteworthy that the experimental data obtained do not allow the one-to-one correspondence between the polarization resistance and the transfer parameters (oxygen permeability, ionic or electronic conductivity) of the materials studied to be ascertained. Specifically, ionic oxygen conductivity of strontium cobaltites-ferrites exceeds the corresponding values of $\mathrm{Ln}(\mathrm{Sr}) \mathrm{CoO}_{3-\delta}$ solid solutions and $\mathrm{Bi}_{0.75} \mathrm{Y}_{0.25} \mathrm{O}_{1.5}$ electrolytes $[8,9,24]$. However, polarization resistance of the $\mathrm{SrCo}_{0.5} \mathrm{Fe}_{0.5} \mathrm{O}_{3-\delta}$ electrodes is substantially above those of $\mathrm{La}_{0.7} \mathrm{Sr}_{0.3} \mathrm{CoO}_{3-\delta}$ and $\mathrm{Nd}_{0.5} \mathrm{Sr}_{0.5} \mathrm{CoO}_{3-\delta}$.

\section{Conclusions}

Interaction of the electrodes consisting of perovskite-like rare earth elements and strontium cobaltites with $\mathrm{Bi}_{2} \mathrm{O}_{3}$-based solid electrolyte has been studied. Such interaction causes changes of chemical and phase composition of materials used. It has been found that formation of solid solutions $\mathrm{La}_{1-x-y} \mathrm{Sr}_{x} \mathrm{Bi}_{y} \mathrm{CoO}_{3-\delta}(x=0-0.5 ; y=0-0.2)$ as well as $\left(\mathrm{Bi}_{1-x} \mathrm{Co}_{x}\right)_{1-,}, \mathrm{Y}_{y} \mathrm{O}_{15}(x=0-0.4 ; y=0-0.25)$ can occur in the diffusion layers between cobaltite electrodes and $\mathrm{Bi}_{2} \mathrm{O}_{3}$-based solid electrolytes. Substitution of lanthanum and strontium with bismuth results in a drop in electrical conductivity and oxygen permeability of cobaltites suggesting that it is necessary to minimize the interaction of cobaltites and bismuth oxide-based solid electrolytes on the applying of electrodes.

\section{Acknowledgments}

This work was supported in part by the Belarus Foundation for Fundamental Researches, the International Soros Science Education Program and the Belarus Ministry of Education and Science. The authors gratefully acknowledge the help of their colleagues A.A. Tonoyan and M.V. Zinkevich in this research. 


\section{References}

[1] B.C.H. Steele, in: Proceedings of the 1st European SOFC Forum, Luceme, Switzerland, vol. 1, 1994, p. 375.

[2] K. Sasaki, M. Goedickemeier, P. Bohac, A. Orliukas, L.J. Gauckler, in: Proceedings of the Sth IEA Workshop, Juelich, Germany (1993) p. 187.

[3] S. Carter, A. Selcuk, R.J. Chater, J. Kajda, J.A. Kilner, B.C.H. Steele, Solid State Ionics 53-56 (1992) 597.

[4] Y. Teraoka, H.-M. Zhang, K. Okamoto, N. Yamazoe, Mat. Res. Bull. 23 (1988) 51.

[5] R.H.E. van Doorn, H. Kruidhof, H.J.M. Bouwmeester, A.J. Burgraaf, Mat. Res. Soc. Symp. Proc. 369 (1995) 377.

[6] H. Tanabe, S. Fukushima, Electrochim. Acta 31 (1986) 801.

[7] H. Nagamoto, H. Inoue, J. Electrochem. Soc. 136 (1989) 2088.

[8] V. Kharton, E.N. Naumovich, P.P. Zhuk, A.K. Demin, A.V. Nikolaev, Electrokhimiya 28 (1992) 1693 (in Russian).

[9] VV. Kharton, E.N. Naumovich, A.V. Nikolaev, VV. Astashko, A.A. Vecher, Russian J. Electrochem. 29 (1993) 1039.

[10] V.V. Kharton, E.N. Naumovich, Russian J. Electrochem. 29 (1993) 1297.

[11] E.N. Naumovich, S.A. Skilkov, V.V. Kharton, A.A. Tonoyan, A.A. Vecher, Russian J. Electrochem. 30 (1994) 642.
[12] V.N. Chebotin, M.V. Perfilyev, in: Electrochemistry of Solid Electrolytes, Khimiya, Moscow, 1978 [in Russian].

[13] V.V. Kharton, A.V. Nikolaev, E.N. Naumovich, A.A. Vecher, Solid State Ionics 81 (1995) 201.

[14] Powder Diffraction File. Swarthmore: Joint Committee on Powder Diffraction Standarts. Card Number 27-1047.

[15] V.V. Kharton, P.P. Zhuk, A.A. Tonoyan, T.E. Zhabko, A.A. Vecher, Neorganicheskie Materialy 27 (1991) 2610 (in Russian).

[16] N. Ramadass, Mat. Sci. Eng. 36 (1978) 189.

[17] V.V. Kharton, E.N. Naumovich, A.A. Vecher, A.V. Nikolaev, J. Solid State Chem. 120 (1995) 128.

[18] E.M. Levin, R.S. Roth, J. Res. Nat. Bur. Std. 68A (1964) 197.

[19] Powder Diffraction File. Swarthmore: Joint Committee on Powder Diffraction Standarts. Card Number 39-871.

[20] H.A. Harwig, A.G. Gerards, Thermochim. Acta 28 (1979) 121.

[21] M.J. Verkerk, A.J. Burgraaf, Solid State Ionics 3 (1981) 463.

[22] H.H. Moebius, in: Extended Abstract of the 37th Meeting of the ISE, Vilnius (1986), USSR, vol. 1, p. 136.

[23] M.V. Perfilyev, Solid State Ionics 9/10 (1983) 765.

[24] B. Ma, J.-H. Park, C.U. Segre, U. Balachandran, Mat. Res. Soc. Symp. Proc. 393 (1995) 49. 